\title{
EDUCAÇÃO, BIOÉTICA E CIDADANIA: APROXIMAÇÕES, CONVERGÊNCIAS E TRANSVERSALIDADES NA PERSPECTIVA DA TEORIA CRÍTICA
}

Nilo Agostini ${ }^{*}$

\begin{abstract}
Resumo: Este texto parte de uma investigação teórica buscando tecer as convergências e transversalidades entre educação, bioética e cidadania, através de algumas de suas interfaces. Parte do diálogo em construção entre os sujeitos ativos nestes campos. Assim, a educação investe no sujeito $e$, permeada pela ética, tece aproximações $e$ identifica transversalidades com a bioética e a cidadania, apostando sempre na emergência do sujeito ético. Capaz de ação e reflexão - ser da práxis - este sujeito investe na transformação da realidade e de si mesmo. Faz da bioética um campo de diálogo que prima pela vida, com atenção à saúde pública. Foca a cidadania como construção histórica, na conquista, incorporação e consolidação de direitos, como é o da saúde. Investe na emancipação dos sujeitos e comunidades, capazes de uma autorreflexão crítica, de assumir compromissos históricos e de buscar alternativas no conjunto da vida social.
\end{abstract}

Palavras-chave: Educação; bioética; cidadania; saúde; ética.

Resumen: Este texto parte de una investigación teórica buscando tejer las convergencias y transversalidades entre educación, bioética y ciudadanía, a través de algunas de sus interfaces. Parte del diálogo en construcción entre los sujetos activos en estos campos. Así, la educación invierte en el sujeto $y$, permeada por la ética, teje aproximaciones e identifica transversalidades con la bioética y la ciudadanía, apostando siempre en la emergencia del sujeto ético. Capaz de acción y reflexión - ser de la praxis - este sujeto invierte en la transformación de la realidad y de sí mismo. Hace de la bioética un campo de diálogo que prima por la vida, con atención a la salud pública. Foca la ciudadanía como construcción histórica, en la conquista, incorporación y consolidación de derechos, como es el de la salud. Invierte en la emancipación de los sujetos y comunidades, capaces de una autorreflexión crítica, de asumir compromisos históricos y de buscar alternativas en el conjunto de la vida social.

Palabras claves: Educación, bioética, ciudadanía, salud, ética.

Introdução

Este texto parte de uma investigação teórica, contemplando a produção bibliográfica realizada nos principais centros de pesquisa do Brasil. Analisamos as

\footnotetext{
* Formado em Teologia, Doutor, Programa Stricto Sensu em Educação da Universidade São Francisco (USF).
}

práticas realizadas e o conhecimento científico produzido. "Educação, bioética e cidadania" é o tema investigado em algumas de suas interfaces, através das quais estabelecemos aproximações, convergências, transversalidades, numa recepção seletiva da grande gama de materiais disponíveis que, dependendo dos 
descritores utilizados, aumenta ou diminui significativamente seu volume.

A questão de fundo não é só a viabilidade de articulação entre educação, bioética, cidadania, mas a de surpreender onde residem os campos de força, capturando os pontos onde eles não podem ser dissociados. Trata-se de capturar a relação de pertinências inclusivas; estas poderiam ser representadas por elipses concêntricas haja vista as mútuas transversalidades aí existentes. É importante notar que, deste modo, superam-se movimentos fragmentados, indo além da racionalidade instrumental tão arraigada historicamente em nossa cultura.

Educação, bioética e cidadania: um desafio que merece ser assumido. $\mathrm{O}$ espaço é de diálogo e de permanente construção. Importa participar como sujeitos ativos $e$ criativos que constroem juntos a história. A educação investe no sujeito $e$, permeada pela ética, tece aproximações e identifica transversalidades com a bioética e a cidadania, apostando sempre na emergência do sujeito ético. Numa ação e reflexão sobre o mundo, este ser humano desdobra a sua capacidade de atuar $e$ refletir. Esta capacidade "o faz um ser da práxis" (Freire, 2007, p. 17). Por meio dela, ele atua, opera, transforma a realidade e a si mesmo, sendo esta a maneira humana de existir. Iniciamos pela bioética que é hoje um grande espaço em construção que necessita de um diálogo amplo com protagonistas os mais diversos. A partir deste espaço inferimos as intersecções com a educação e a cidadania.

\section{Bioética: espaço de diálogo em construção}

Em primeiro lugar, olhamos para a vida; esta aparece como referência primeira para viver neste mundo. Toda a busca de justiça nos faz erguer uma morada, qual ethos, que tenha a vida, sustentada na amorosidade, como o seu chão primeiro. É onde intervêm a educação e a ética. "Não é possível pensar os seres humanos longe da ética" (Freire, 2014, p. 34), pois o compromisso é sempre com "um mundo a ser humanizado para a humanização dos homens" (Freire, 2007, p. 18). Trata-se, então, de perfazer por primeiro o itinerário de uma bio-ética, desafio de monta lançado à própria educação, em meio ao exercício da cidadania dos insurgentes de nossos tempos.

A bioética é o espaço de diálogo que se abre entre buscas diversas, práticas distintas e interlocutores vários, em vista de uma ação comprometida e decidida em 
favor da vida, quer pela salvaguarda da dignidade humana quer pelo cuidado da criação.

\section{Várias frentes no desdobramento da bioética}

Desde cedo, vimos a bioética desdobrar-se em várias frentes (Agostini, 2003) e estabelecer múltiplas interfaces. Ela não possui um receituário (Garrafa, 1995). Tem como base a ética aplicada, portanto prática; abre discussões, analisa casos, confronta ideias, argumenta com a razão; porém, está aberta a diferentes olhares, tendências; acompanha o momento histórico, o desenvolvimento tecnológico, a situação político-social e suas estruturas. Busca respostas equilibradas aos conflitos, ciente da não neutralidade da ciência, buscando abordagens plurais, inter, pluri $e$ transdisciplinares, em meio a uma realidade complexa.

Numa de suas frentes, vimos a bioética ocupar-se das questões de fronteira, suscitadas pelo desenvolvimento das ciências e das tecnologias, sobretudo no campo biotecnológico. O impacto deste desenvolvimento na vida humana e na sociedade é enorme, exigindo a análise de suas implicações éticas e sociais. No caso do desenvolvimento dos conhecimentos relativos à engenharia genética, ligados aos da biologia molecular, abrem-se campos de intervenção, impensáveis até há pouco tempo. Por um lado, vislumbramos horizontes fascinantes; por outro lado, entrevemos desafios novos e problemas diversos. Chegamos à possibilidade de manipular as informações genéticas e de transformá-las. Interrogações, porém, não faltam. Os desafios éticos são numerosos. A missão do ser humano ante tal conhecimento precisa ser respaldada por delimitações a favor da vida. Não basta competência tecnocientífica; os conhecimentos chegarão a ser devidamente aplicados a favor da vida se forem fundados na ética.

Outra frente da bioética foi a que passou a se ocupar das questões do cotidiano. Amplia-se, assim, o campo do paradigma bioético. Este prima pelo respeito à vida, buscando defender condições compatíveis à dignidade da pessoa humana. Especial desafio provém das condições de vida das populações mais carentes, sobretudo da dura realidade da fome e da miséria, revelando muitas situações de vulnerabilidade. Esta costuma conjugar-se com a precariedade nas áreas da saúde, saneamento básico, água, alimentação, habitação, educação, trabalho, 
segurança etc. Somam-se questões oriundas das várias faces da discriminação (social, racial, de gênero e outras), do submundo das drogas, da violência, do desemprego etc. A precariedade na qual se encontra nossas populações não é uma mera fatalidade, mas é fruto de estruturas que perderam de vista o bem comum, atentam contra a dignidade da pessoa humana $e$ seus direitos fundamentais, destroem a vida.

Não tardou que a bioética incluísse o desafio ecológico como uma de suas frentes de práticas, estudo e discussão, resultante da crescente consciência do compromisso ético do ser humano face à natureza, haja vista o aumento de sua intervenção depredadora. O horizonte bioético capta a interação ser humano-natureza, bem como a inclusão de todos os seres vivos $e$ não vivos como parte de uma criação na qual tudo se relaciona e se inclui. Antes de ser uma crise ecológica, nos defrontamos com a crise do próprio ser humano e sua civilização, segundo a qual a natureza é concebida como "aquilo que pode ser conhecido e objetivado experimentalmente, manipulado e utilizado tecnicamente" (Simon, apud Siegwalt, 1980, p. 11). Isto acaba nos levando ao nó da crise que é a intervenção depredadora do ser humano ante a realidade (limitada) da Terra. O processo acaba sendo de desnaturação e de desumanização.

\section{Interfaces a partir do diálogo bioética $e$ saúde coletiva}

Na experiência brasileira, está sendo relevante o diálogo entre bioética e saúde coletiva; este diálogo revela interfaces que estão propiciando um desenvolvimento à medida que passam a se relacionar temas como equidade em saúde e direito à saúde (Vieira \& Verdi, 2011). Estas interfaces estão auxiliando no processo de criação, reflexão e consolidação da bioética no Brasil, nas quais se revelam várias tendências que "procuram, de forma politizada, construir um país melhor, com justiça social e solidariedade, a fim de melhorar a qualidade de vida" (Vieira \& Verdi, 2011, p. 23). Neste caso, como explica Garrafa (1995, p. 9), a bioética passa a ser entendida como a "resultante moral do conjunto de decisões e medidas políticas e sanitárias - individuais e coletivas - que proporcionam aumento da cidadania e diminuição da exclusão social" (Vieira \& Verdi, 2011, p. 9).

Torna-se imprescindível o exercício da reflexão ética, sobretudo ante um pluralismo de ideias e comportamentos, 
num espectro amplo de escolhas livres, em grande parte fundadas nos próprios direitos humanos (Berlinguer, 2004). Sente-se, não raro, a necessidade de ampliar os temas da bioética, redirecionar as atuais orientações a fim de incluir "uma ética da saúde que não signifique somente deontologia médica atualizada ou reflexão sobre os limites extremos da vida e da morte, mas que esteja também relacionada aos princípios $e$ à prática de todos os atores e temas da saúde cotidiana" (Berlinguer, 2004, p. 21). A bioética abre-se assim às condições de vida no cotidiano das pessoas, atenta aos acontecimentos do dia-a-dia, aos direitos a serem salvaguardados, normalmente assegurados nas democracias.

$\mathrm{Na}$ América Latina, somos igualmente atentos às heranças culturais de nossos povos e seu modo próprio de organizar a vida $e$ de enfrentar os problemas cotidianos. Não nos bastam as referências teóricas principialistas, fundadas na autonomia. Numa reanálise históricocultural, damo-nos conta que temos dilemas que nos fazem repensar a bioética, tais como autonomia versus justiça/equidade, omissão versus participação, entre outros (Garrafa, Kotow, \& Saada, 2006). A redemocratização de nossos países, alimentada pelos movimentos e lutas sociais que incluem também a saúde coletiva, requer uma democratização do Estado e de seus aparelhos, numa democracia substantiva $e$ progressiva que inclua os cidadãos e reconheça sua emancipação na conquista de uma vida mais saudável.

Esta perspectiva está em construção, numa perspectiva científica que aciona interdisciplinarmente os saberes, nas áreas das ciências biológicas, humanas e sociais. Abre-se a novos paradigmas, sem negar o acúmulo teórico-reflexivo já realizado. As "práticas são informadas nos valores que prezam a democracia, a emancipação $e$ a solidariedade..., em compromissos históricos com o povo, com as pessoas, com as classes dominadas" (Paim, J. S., 2007, p. 2521-2). O enfoque é ampliado para a coletividade, sendo revista a posição exclusivamente ancorada na autonomia. Tem-se em conta "o bem-estar da população, com garantia da qualidade de vida das pessoas" (Junqueira, \& Junqueira, 2009, p. 97). A bioética passa a ser compreendida na perspectiva da cidadania.

\section{Cidadania: sujeitos que participam $e$ constroem a história}

$\mathrm{Na}$ perspectiva da cidadania, a bioética leva em conta o resgate dos direitos humanos e funda-se na ética como 
"condição dinâmica que emerge na constante interação com o ambiente onde estamos inseridos" (Urtiaga, 2002, p. 3). A cidadania realiza-se como construção histórica, na conquista, incorporação $e$ consolidação de direitos, como é o da saúde.

\section{A cidadania como construção}

Ao falar de cidadania, não estamos diante de uma palavra com sentido unívoco. Mesmo assim, ela está ligada à consciência e à fruição de direitos, evocando igualmente deveres correspondentes. Não se trata de um dado estático; ela é antes uma construção. Há quem prefira falar em extensão da cidadania, enquanto luta pela incorporação, ampliação e/ou conquista de direitos.

"Na Idade Moderna observa-se, claramente, o processo da conquista da cidadania. Três séculos foram necessários para que se incorporassem ao conceito de cidadania (pelo menos sob o ponto de vista formal) os direitos civis (século XVIII), os direitos políticos (século XIX) e os direitos sociais (século XX)" (Gueiros, 1991, p. 23).

Sendo um processo, a cidadania representa, ao mesmo tempo, "a incorporação de novos grupos ou classes ao gozo de direitos já reconhecidos e/ou a incorporação de novos direitos aos já existentes" (Gueiros, 1991, p. 23). Este processo não é simples nem fácil, pois de facto a questão da cidadania está associada à consolidação democrática. Por vezes, ela traz características ausência de cidadania; outras vezes, nos deparamos com uma cidadania ainda excludente; e, em não poucos casos, nos encontramos em meio a uma cidadania regulada (Benevides, 1994).

Vivemos, na realidade, sob o peso de um conjunto de obstáculos à cidadania $e$ à sua extensão, consequência de toda uma tradição oligárquica, autoritária, populista e corporativista, aliada a um sistema eleitoral/político calcado na pura representação, sem real participação e/ou intervenção do cidadão.

Na concepção moderna, o cidadão é um indivíduo portador de direitos $e$ deveres, fixados por uma estrutura legal. Ao mesmo tempo, os cidadãos são livres $e$ iguais perante a lei. No entanto, a realidade é bem outra. No capitalismo, a evolução histórica dos direitos do cidadão revela uma tensão e distorção entre o princípio de igualdade $e$ as desigualdades a ele inerentes. No liberalismo, o que é direito descamba facilmente para a categoria de concessões ou simplesmente benesses para protegidos, tutelados, clientelas. 
Não basta uma cidadania passiva, com um Estado doador de direitos ou com sistemas que fazem concessões, numa cidadania regulada, segundo os interesses das classes dominantes. Não basta uma cidadania outorgada pelo Estado, que mais lembra a ideia de favor e de tutela. Impõese uma cidadania ativa, na qual o cidadão, além de portador de direitos e deveres, é criador/construtor de direitos, exige instituições, mediações e espaços de participação para a consolidação social $e$ política dos mesmos.

\section{$\mathrm{O}$ direito à saúde}

$\mathrm{Na}$ imbricação bioética e cidadania, surge como conquista crescente o direito à saúde. No Brasil, por exemplo, esse direito foi garantido pela Constituição cidadã de 1988, o que deu origem ao Sistema Único de Saúde (SUS). Mais recentemente, no campo científico, houve todo um trabalho em prol da saúde coletiva. A noção de direito à saúde pressupõe condições básicas para uma boa saúde; engloba também o acesso igualitário aos diferentes recursos, por exemplo financeiros, tecnológicos $e$ humanos. Porém, com recursos escassos, é difícil uma distribuição pautada pela equidade, tornando necessária a criação de políticas públicas que privilegiem o acesso a grupos vulneráveis (Junges, 2009, p. 286). A grande discussão passa então a ser quais são os critérios de justiça no acesso a esses recursos.

O direito à saúde está assentado nos três valores básicos, acima citados, a liberdade, a igualdade e a participação, expressões dos próprios direitos humanos em sua indivisibilidade e interdependência.

Por um lado, a saúde encontra-se entre os direitos indispensáveis para o exercício de outros direitos humanos; por outro lado, ela é condição para uma vida digna e depende igualmente da realização de outros direitos. Para isto, faz-se necessário cultivar uma visão integral do ser humano que compreenda a integração e o equilíbrio de todas as suas dimensões, quer somática e psico-afetiva, quer comunitáriosocial e espiritual.

O núcleo central passa a ser a qualidade de vida, numa noção pluridimensional, incluindo tanto os aspectos individuais como coletivos, como realização da cidadania e da promoção da vida. Identificamos aqui uma dupla interdependência entre o individual e o coletivo, indispensável quando se fala em direito à saúde. Não podemos separá-los, nem opô-los, pois se exigem mutuamente. 
Isto se explicita num direito que é de defesa ou proteção, tutelando a liberdade dos indivíduos, inclusive frente ao Estado, e num direito que é de prestação que obriga o Estado à efetivação de bens e serviços.

O direito à defesa está mais enfocado no indivíduo em sua liberdade, enquanto o de prestação está voltado mais para a exigência da construção de instrumentos no coletivo como condição para a efetivação dos direitos. Assim, por sua inter-relação com os outros direitos, pode-se dizer que o direito à saúde tem também uma dimensão de defesa $e$ de prestação [...]. Portanto, o direito à saúde precisa conjugar a proteção da autonomia individual e a prestação coletiva de meios para efetivação desse direito (Junges, 2009, p. 288).

\section{Educação para a bioética $e$ para a cidadania}

A educação coloca "o sujeito como centro do seu processo" (Silva \& Prata, 2013, p. 9), numa educação para os valores e para a cidadania, sendo promotora de saúde, tendo clareza nas suas proposições diretoras ou princípios, bem como nos eixos teórico-metodológicos adotados.

\section{Educação e bioética}

A interface educação e bioética apresenta-se como necessária, assim preconizada pela própria Unesco:
Para alcançar uma melhor compreensão das implicações éticas dos avanços científicos e tecnológicos, em especial para os jovens, os Estados devem envidar esforços para promover a formação e educação em Bioética em todos os níveis, bem como estimular programas de disseminação de informação e conhecimento sobre Bioética (UNESCO, 2005, art. 23). Importa desenvolver uma pedagogia problematizadora, sendo a bioética um importante instrumento, capaz de "desenvolver a percepção ética, desenvolver habilidades de raciocínio analítico, levantar um senso de responsabilidade pessoal e lidar com a ambiguidade moral" (Silva, 2011). E, diante de dilemas morais, cabe

proporcionar aos alunos várias perspectivas das questões e guiá-los ao próprio processo de raciocínio em direção a conclusões que nem todos (nem mesmo o professor) irão necessariamente concordar, mas que podem ficar sob escrutínio e diálogo aberto com os outros alunos (Jennings, 1991, p. 5).

Cabe investir numa "educação moral democrática" (Cortina \& Martinez, 2005, p. 170), aliando habilidade técnica e habilidade social com uma fundamentação em valores, tais como a autonomia $e$ a solidariedade. Porém, se educamos só para o próprio bem-estar, basta uma educação baseada na racionalidade instrumental. 
"Mas se buscamos a formação de pessoas autônomas com desejo de auto-realização, então é necessária uma educação moral, no mais amplo sentido da palavra "moral"" (Cortina \& Martinez, 2005, p. 170).

Esta educação não é completa se enfatizar apenas aspectos informativos em vista de uma capacitação puramente intelectual e profissional, calcada numa racionalidade instrumental. Aqui, faz-se necessário "uma abordagem mais humanista e reflexiva, isto é, aspectos mais formativos e criativos", bem como "uma consciência ética e crítica do mundo" (Silva, 2011). Esta educação leva à solidariedade, fundada nas relações entre as pessoas, num olhar para os mais vulneráveis que necessitam de proteção na preservação do seu bem maior que é a vida. É o momento em que a educação e a bioética se abrem para uma nova interface, a cidadania. Unindo conhecimento e poder, importa educar "cidadãos críticos e ativos" (McLaren, 1997, p. 192).

\section{Educação, cidadania e saúde}

Teóricos educacionais críticos, como Peter McLaren, são enfáticos e entendem o papel da educação como a capacidade de unir conhecimento e poder "no desenvolvimento de cidadãos críticos $e$ ativos" (McLaren, 1997, p. 192).

A cidadania aparece como um objetivo da educação para a saúde. A conjugação destes elementos permite a "problematização e reflexão da realidade", "a capacitação e criticidade para a tomada de decisões", "a construção da consciência crítica", "a conquista da cidadania" (Leite \& Tonolli, 2010), a "preocupação por cidadãos educados, críticos e comprometidos" (McLaren, 1997, p. 193). A escola passa a ter destaque como "formadora ética e de cidadania", levando "o educando a compreender a necessidade de um contínuo pensar, refletir e construir, o que favorece o exercício da cidadania" (Santos, 2005, p. 167, 175). Cabe à escola ser promotora de saúde, à medida que contribui para a "aquisição de capacidades e competências individuais e coletivas" (Silva \& Prata, 2013, p. 5) num duplo objetivo, ou seja, "desenvolver hábitos saudáveis e possibilitar o pleno exercício da Cidadania" (Moura, 2007, p. 496).

As escolas passam a ser lugares onde se cultiva "um mundo radicalmente diferente", no sentido de "curar, consertar e transformar o mundo" (McLaren, 1997, p. 192). 
As escolas deveriam ser locais para a transformação social e emancipação, lugares onde os estudantes são educados não somente para serem pensadores críticos, mas também para verem o mundo como um lugar onde suas ações podem fazer a diferença (McLaren, 1997, p. 194).

A percepção que se tem da educação para a cidadania identifica elementos que lhe são favoráveis como identidade, pertencimento e conhecimentos, constituindo "eixos de articulação entre educação para a cidadania, promoção da saúde, enquanto educação em saúde" (Silva \& Prata, 2013, p. 5).

Assim, ao produzir criticidade e sentido de comunidade, tornam-se componentes constitutivos do exercício da cidadania [...], já que atuam como promotores diretos do empoderamento, um dos mecanismos constitutivos da promoção da saúde (Silva \& Prata, 2013, p. 5).

Segundo McLaren (1997), cabe decifrar o papel que "as escolas de fato representam dentro de uma sociedade dividida em raça, classe e gênero" (p. 195), questionando experiências, textos $e$ ideologias apolíticas e pretensamente neutras, que acabam por "reproduzir os valores e privilégios das elites existentes" (p. 195-196).

A pedagogia crítica compromete-se com formas de aprendizado $e$ ação empreendidas em solidariedade com grupos subordinados e marginalizados. $\mathrm{Em}$ adição ao questionamento dos conceitos estabelecidos sobre a escolarização, os teóricos críticos se dedicam aos imperativos emancipatórios de conferir poder ao indivíduo e de transformação social (McLaren, 1997, p. 196) ${ }^{1}$.

\section{Conclusão}

A aproximação de "educação, bioética e cidadania", das suas pertinências inclusivas e mútuas transversalidades nos levam a identificar um processo de criação, reflexão, consolidação da bioética, enquanto espaço de diálogo no encontro entre ciência e ética, seus desdobramentos e interfaces, tais como a bioética e saúde pública. Igualmente, valorizamos a cidadania em seu caráter transversal e a educação como formadora ética e cidadã, bem como promotora de saúde.

A cidadania coloca a bioética no coração da vida, como construção histórica, ancorada nos direitos humanos, à medida que se expressa, na práxis, a conquista, a incorporação e a consolidação de direitos, como é o da saúde. Assenta-se nos valores da liberdade, da igualdade $e$ da participação, como implementação democrática. Explicita o direito à saúde como proteção e como prestação, atenta aos determinantes sociais. No centro está a

\footnotetext{
${ }^{1}$ Reproduzimos o itálico do próprio texto original.
} 
noção de qualidade da vida que se explicita numa vida digna e na realização de outros direitos. Isso requer acesso igualitário aos diferentes recursos e políticas públicas que garantam o acesso a grupos vulneráveis. Depara-se igualmente com a entrada em cena do biopoder, como forma do mercado pretender controlar a saúde, regulando $e$ ajustando as populações aos processos econômicos por meio agenciamentos tecnosemiológicos.

A educação, toda atravessada pela ética, coloca, como seu foco, a formação do sujeito ético, capaz de uma autorreflexão crítica, de assumir compromissos históricos e de buscar alternativas no conjunto da vida social. A bioética explicita-se como terreno propício para a educação nos valores; alia habilidade técnica e social com percepção ética e raciocínio analítico. Não basta a racionalidade instrumental; faz-se necessário uma educação que explicite a responsabilidade pessoal e social e leve ao compromisso e à solidariedade. Entramos no âmbito de uma educação para a cidadania que estabelece importante elo com a mudança paradigmática no campo da saúde, assimilado pela bioética, interligando educação em saúde com educação para a cidadania.
Importa investir no conhecimento emancipatório e, numa ação reflexiva, detectar "como os relacionamentos sociais são distorcidos e manipulados por relações de poder e privilégio", buscando superar "a irracionalidade, a dominação e a opressão" para criar "as bases para a justiça social, igualdade e distribuição de poder" (McLaren, 1997, p. 203-204).

Com as abordagens acima, suplantamos uma bioética acrítica, numa leitura puramente dedutiva de princípios que trata apenas do indivíduo. Volnei Garrafa aponta para uma "bioética interventiva, crítica e socialmente comprometida", o que vem sendo "incorporado por bioeticistas latinoamericanos críticos em suas reflexões, estudos e pesquisas" (Garrafa, 2005, p. 130). Garrafa funda sua concepção em "categorias como 'responsabilidade', 'cuidado', 'solidariedade', 'comprometimento', 'alteridade' e 'tolerância', dentre outras", além das que ele chama de quatro "pês"; vejamos:

- prevenção (de possíveis danos e iatrogenias), precaução (frente ao desconhecido), prudência (com relação aos avanços e "novidades") $e$ proteção (dos excluídos sociais, dos mais frágeis e desassistidos) - para o exercício de uma prática bioética comprometida com os mais vulneráveis, com a "coisa pública" $e$ com o equilibrio ambiental $e$ 
planetário do século XXI (Garrafa, 2005, p. 130).

A grande questão, que vem pontuada com clareza pela pedagogia crítica, está numa escolha que temos que fazer como professores e cidadãos. Mclaren (1997, p. 190) a pontua da seguinte forma: "Queremos que nossas escolas criem uma cidadania passiva e livre de riscos, ou uma cidadania politizada, capaz de lutar por várias formas de vida pública e informada por uma preocupação com igualdade $e$ justiça social?" Importa "curar, consertar e transformar o mundo; todo o resto é comentário" (McLaren, 1997, p. 192).

\section{Referências}

AGOSTINI, N. Bioética: delimitações protetoras da vida. Revista Communio, v. 18, n. 87, p. 137-158, 2003.

Ética: diálogo e compromisso. São Paulo: FTD, 2010.

BENEVIDES, M. V. de M. Cidadania e Democracia. Lua Nova. Revista de Cultura e Política, v. 33, p. 5-16, 1994.

BERLINGUER, G. Questões de vida. Ética, ciência, saúde. São Paulo: APCE/Hucitec/CEBES, 2993.

2004. . Bioética cotidiana. Brasília: UNB,

BORDENAVE, J. D. O que é participação. São Paulo: Brasiliense, 1986.

BUSS, P. M. Promoção da saúde $e$ qualidade de vida. Ciência \& Saúde Coletiva, v. 5, n. 1, p. 163-177, 2000.

CORTINA, A., \& MARTINEZ, E. Ética. São Paulo: Loyola, 2005.
DUSSEL, E. Filosofia da libertação: crítica à ideologia da exclusão. São Paulo: Paulus. 1995.

FERREIRA A. B. H. Novo Dicionário da Língua Portuguesa. (2a ed.) Rio de Janeiro: Nova Fronteira, 1986.

FOUCAUL, M. Microfísica do poder. Rio de Janeiro: Graal, 2001.

FREIRE, P. Educação e mudança. $30^{\mathrm{a}}$ ed. São Paulo: Paz e Terra, 2007.

Pedagogia da autonomia: saberes necessários à prática educativa. $49^{\mathrm{a}}$ ed. Rio de Janeiro: Paz e Terra, 2014.

GARRAFA, V. Dimensão da Ética em Saúde Pública. São Paulo: Universidade de São Paulo, Faculdade de Saúde Pública, 1995.

- Da bioética de princípio a uma bioética interventiva. Bioética, v. 13, n. 1, p. 125-134, 2005.

GARRAFA, V., KOTTOW, M., \& SAADA, A. Bases conceituais da Bioética: enfoque latino-americano. São Paulo: Gaia, 2006.

GUEIROS, M. J. G. Serviço Social e Cidadania. Rio de Janeiro: Agir, 1991.

HOTTOIS, G. Qu'est-ce que la bioéthique? Paris: Vrin, 2004.

HUBER, W. Direitos humanos: um conceito e sua história. Concilium, n. 144, p. 7-17, 1997.

JENNINGS, B. et al. New Choices, New Responsibilities: Ethical Issues in the Life Sciences: A Teaching Resource on Bioethics for High School Biology Courses. USA: Hastings Center, Ringbound edition, 1991.

JUNGES, J. R. Direito à saúde, biopoder e bioética. Interface - Comunicação, Saúde, Educação, v. 13, n. 29, p. 285-295, 2009.

JUNQUEIRA, S.R., \& JUNQUEIRA, C.R. Bioética e saúde pública. In: RAMOS, D. L. 
P. (Ed.). Bioética, pessoa e vida. São Caetanos do Sul: Difusão, p. 78-92, 2009.

LA TAILLE, Y., SOUZA, L., \& VIZIOLLI, L. Ética e educação: uma revisão da literatura educacional. Educação e Pesquisa, v. 30, n. 1, p. 91-108, 2004.

LEITE, S. N., \& TONOLLI, L. M. Uma terceira via para a gente aprender as coisas femininas... perspectivas sobre o desenvolvimento de um projeto de promoção de saúde e cidadania de meninas. Interface - comunicação, saúde, educação, v. 14, n. 35, p. 933-942, 2010.

LIPOVETSKY, G. O crepúsculo do dever. A ética indolor dos novos tempos democráticos. Lisboa: Dom Quixote, 1994.

MCLAREN, P. A vida nas escolas: Uma introdução à pedagogia crítica nos fundamentos da educação. $2^{\mathrm{a}}$ ed. Porto Alegre: Artes Médicas, 1997.

MORIN, E. (1984). Ciência com consciência. Portugal: Europa-América, 1984.

MOURA, J. B. V. S. et al. Perspectiva da epistemologia histórica e a escola promotora de saúde. História, Ciências, Saúde - Manguinhos, v. 14, n. 2, p. 489501, 2007.

NOGUEIRA, R.P. Higiomania: a obsessão com a saúde na sociedade contemporânea. In: VASCONCELOS, E. M. (Ed.). A saúde nas palavras e nos gestos: reflexóes da rede educação popular e saúde. São Paulo: Hucitec, p. 63-72, 2001.

PAIM. J. S. Saúde coletiva como compromisso: a trajetória da Abrasco. Caderno Saúde Pública, v. 23, n. 10, p. 2521-2, 2007. Disponível em:

http://www.scielo.br/scielo.php?script=sci_a $\underline{\text { rttext\&pid =S0102-311X2007001000030. }}$ Acesso: 01/08/2016.
RODRIGUES, N. Educação: Da formação humana à construção do sujeito ético. Educação \& Sociedade, v. 76, n. 22, p. 232-257, 2001.

SANTOS, E. V. M. Cidadania, conhecimento, ciência e educação CTS: Rumo a "novas" dimensões epistemológicas. Revista CTS, v. 2, n. 6, p. 137-157, 2005.

SAUL A. M., \& SILVA, A. F. G. Uma leitura a partir da epistemologia de Paulo Freire: a transversalidade da ética na educação, currículo e ensino. Revista Cocar, v. 6 n. 11, p. 7-15, 2012.

SEVERINO, A. J. A busca de sentido da formação humana: tarefa da filosofia da Educação. Educação e Pesquisa, v. 32, n. 3, p. 619-634, 2006.

SFEZ, L. A saúde perfeita: crítica de uma nova utopia. São Paulo: Loyola, 1996.

SIEGWALT, G. L'université, les sciences et la théologie: Un projet de dialogue interdisciplinaire. In: SIEGWALT, G. (Ed.). La nature a-t-elle um sens? Civilisation technologique et conscience chrétienne devant l' inquiétude écologique. Strasbourg: CERIT, p. 7-14, 1980.

SILVA, P. F. Formação em bioética: proposta para uma educação em valores. Revista Pandora Brasil, v. 28, 2011. Disponível em:

http://revistapandorabrasil.com/revista_pand ora/seculo/paulo.pdf. Acesso: 01/08/2016.

SILVA, E. M., \& PRATA, R. V. Educação em saúde e cidadania: uma análise das articulações das ideias de cidadania nos periódicos de educação em saúde: Atas do IX Encontro Nacional de Pesquisa em Educação em Ciências - IX ENPEC, Águas de Lindóia, SP: Associação Brasileira de Pesquisa em Educação em Ciências, 2013. Disponível 
www.nutes.ufrj.br/abrapec/ixenpec/arquivos Livro WEB.pdf. Acesso em: 10/08/2016.

UNESCO. Declaração Universal sobre Bioética e Direitos Humanos. Brasília: Cátedra Unesco da UnB, Sociedade Brasileira de Bioética, 2005.

URTIAGA, M. E. O. Ética, Bioética e cidadania. Revista Acadêmica de Medicina, v. 7, n. 1/2, p. 3-4, 2002.

VIEIRA, J. B., \& VERDI, M. I. M. Interfaces entre Saúde coletiva e bioética a partir de um estudo da publicação de autores vinculados à pós-graduação em saúde coletiva no Brasil. Interface - Comunicação Saúde Educação, v. 15, n. 36, p. 21-37, 2011.

VILANOVA, R. A. Cidadania nos livros didáticos de ciências: mudança discursiva, mediações e tensões na dinâmica de produção das coleções didáticas para a educação pública. Tese de Doutorado em Educação, Rio de Janeiro: Pontifícia Universidade Católica, 2011.

Recebido em: 09/03/2018

Aprovado em: 10/04/2018 